\title{
Climate Change Geoengineering
}

PHILOSOPHICAL PERSPECTIVES, LEGAL ISSUES, AND GOVERNANCE FRAMEWORKS

Edited by

WIL C. G. BURNS

Johns Hopkins University

ANDREW L. STRAUSS

Widener University School of Law 


\title{
Political Legitimacy in Decisions about Experiments in Solar Radiation Management
}

\author{
David R. Morrow, Robert E. Kopp, and Michael Oppenheimer
}

\section{IN'TROIDUC'IION}

lior better or for worse, geoengineering has moved from the fringes of the climate change debate to the halls of Capitol Hill and Westminster. Of course, a great deal of research remains to be done before the world decides whether to introduce geoenginecring as a complement to mitigation and adaptation; academics and policy makers are still wrestling with the scientific, political, legal, social, and ethical questions surrounding the intentional modification of the climate. Here we address the institutional aspects of some of the cthical issues raised by research on geoenginecring.

The most ethically challenging form of geoenginecring rescarch involves solar radiation management (SRM), which attempts to reduce the cartlis absorption of incoming solar radiation. One proposed mechanism for SRM is the injection of acrosols into the stratosphere, which would deflect more solar radiation back into space. In contrast to research into carbon dioxide removal (CDR), which is the ollurer main caltegory of proposed geocngineering activities, SRM research is parlicularly challenging ethically because studying and testing SRM technologies can recuire deployment at scales that could have significant regional or global climatic effects.t For instance, testing the effects of stratospheric acrosol injection would require lofting enough aerosols into the atmosphere, over a long chough period of

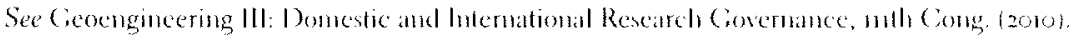

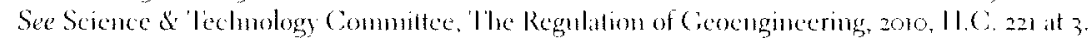
Some earlier work, inclueling ours, refers to SRN as "short-wave clinate chginecring." We regard these wo lerms as synomymots. See David R. Morrow, Rolsert L: Kopp \& Michacel Oppenlucimer, Toward lithical Norms and Institutions for Climate lingineering Research, + FNVTI. RtS. W.TTERS

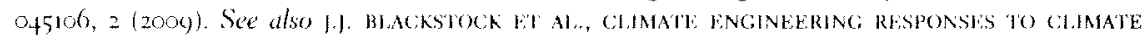
LAIRERNCHIS 2 (2000).

+ Hidckstock el al., supro note 3 , at 25.
} 
lime, to distinguish the effect of the acousts from nomal climatic variation. "The consequences of such large-scale lestim, could cause serious harm to millions of people. For instance, SRM could change regional precipitation patterns, threatening water supplies and agriculture." Morcover, whereas CDR aims to return the atmosphere to an carlier, familiar state, SRM aims to create a new state - one of high greenhouse gas (CHC) concentrations and reduced insolation - about which we know much less.

In an carlier paper we suggested three ethical principles for SRM research based on established principles for biomedical research with human subjects. The analogy between SRM and biomedical research is, like all analogies, imperfect. In this chapter, we consider some of the ethical implications of one limitation of that analogy - nancly, the fact that decisions to participate in biomedical experiments are made individually, whereas the decision to "participate" in an SRM experiment is a collective decision. Specifically, we explore the possibility of designing an international institution that would have the noral authority to make collective decisions about SRM experiments. We consider the requisite features of such an institution and examine the characteristics of other global governance institutions as comparable cises.

\section{THE BIOMEDICAL MODHL FOR SRM RESEARCH EIHICS}

In onr carlier paper, we proposed a basic framework for SRM rescarch ethics that derives from principles governing biomedical research with human and animal subjects."

We intend our framework to apply to large-scale SRM experiments. Very roughly, "large-scale SRM experiments" are experiments that are large enough to significantly alter the climate regionally or globally by changing the rate at which the earth absorbs incoming solar radiation, but smaller than would be deployed to connteract the radiative forcing of anthropogenic (GHCs on a global basis. For instance, injecting enough aerosols into the stratosphere to distinguish their effect from normal climatic variation" constitutes a large-scale SRM experiment; releasing a few tons of

Morrow et al., supra note 3 , at 6 .

"Alan Robock et al., A Test for Geoengineering? 327 sc1. 530, 531 (2010). See also Cevindlasany Bala, K. Caldeira \& R. Nemani, Fast versus Slow Response in Climate Change: Implications for the

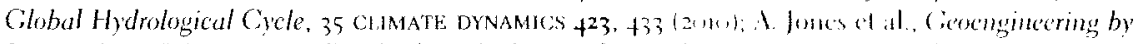

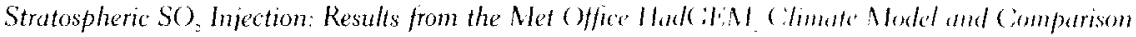

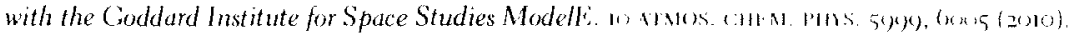

Jones et al., supra note 6 ; Id. at 1 .

Morrow ct al., supra note 3 , at $3-6$.

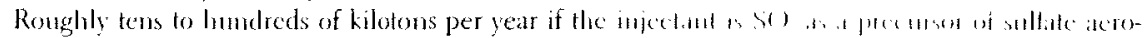

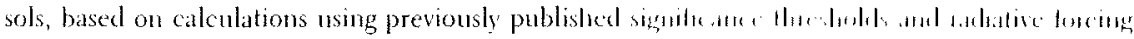


aerosels from a single airplane to observe their physical and chennical reactions with other particles does not, as such a surall quantity of material could not significantly alter the climate. 'Throughout this chapter, we use "SRM experiment" to refer specifically to large-scale activities. We explicitly exclude climate modeling studies and small-scale field tests of SRM technologies, although we recognize that the line between small-scale feld tests and large-scalc experiments is fuzzy.

Our ethical franework for SRM experiments includes three basic principles: The Principle of Respect requires that researchers secure the global public's consent, in some alppropriate form, before commencing an experiment." 'The Principle of $B$ ineficence and Justice requires that researchers protect the basic rights of persons affected by their experiments, minimize the risk-benefit ratio of those experiments, and aim to distribute those risks and benchits justly across persons, animals, and ecosystcms." "The Principle of Minimization requires that experiments should not last longer, cover a greater geographic area, or exert a greater influence on the climate than is necessary to test the specific hypotheses in question. ${ }^{2}$

'The analogy between SRM and biomedical research is, like all analogies, imperfect. The key limitation of this analogy is that individuals decide for themselves whether to participate in and face the risks of a biomedical experiment, whereas we must decide collectively whether to subject ourselves to the risks of an SRM experiment. Imagine two people who are considering participating in a trial of an experimental antidepressant. 'The first person's decision about whether to participate has no effect on the other's decision; it neither precludes nor requires that the other person participate. 'lluus, the first person's decision does not cxpose the second to any risks. SRM is different. "lo "participate" in an SRM experiment, in the relevant sense, is to be subjected to the alteration of the climate. 'l'hus, no one can participate in the experiment unless everyone participates in the experiment. In this respect, an SRM experiment is more like a public health intervention or collective social policy than it is a medical experiment. For example, individuals cannot easily opt out of mandatory vaccination policies, the fluoridation of drinking water, or national pension schemes.

The necessity of "collective participation" in SRM experiments changes the way we think about risk and consent. In the bionedical case, we need to consider only the risks to the individual participant (and, in some cases, his or her family). With SRM, we need to consider both the scale and the distribution of risks. In the biomedical casc, we can and should require the informed consent of each participant. If

estimates. For significance thresholds, see id at 7; for radiative forcing estimates, see Alan Robock et al., Tropical and Arctic Cenengineering, 133 . Cro. REs. Di6101, at 4 (2008).

Norrow et al., supra note 3 , al $f^{-5}$.

"Id. at 5-6.

$\therefore$ Id. at 6 . 


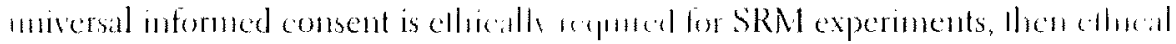

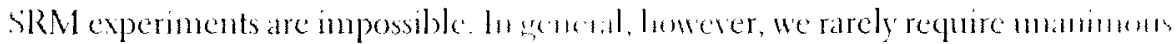

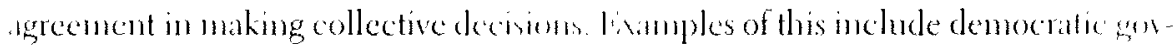
crinnents that sometimes impose militan service requirements, change lat rales, institute redistributive social safety uets, protect species or ecosystems, and prohibil or regulate the use of certain teclmologies, cven when significant fractions of Ile population do not and would not consent to those policies. ho discussing consent and SRM experincuts, we suggested that some indirect form of consent - such ats

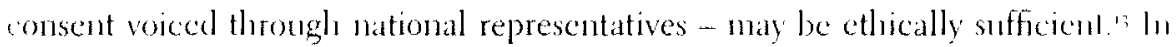
what follows, we consider the features that an institution would need in order lo serve as a velicke for such indirect consent.

\section{COLLECTIVE DECISIONS, LEGITIMACY, AND}

GLOBAL GOVHRNANCH

We contend that in collective decisions, the central nonmative concen is the legitimacy of decisions and decision makers rather than miversal individual consent. I'hus. the ethical conduct of SRM research requires an institution that has the obal political legitimacy to make decisions about SRM experiments.

Political philosophers recognize both a normative and a descriptive (i.c., positive) concept of legitimacy. Roughlily, an institution is legitimate in the normative scuse if it has the right to govern, and it is legitimate in the descriptive sense if it is widcly believed to have the right to govern." Because the ethical conduct of SRM rescarch depends on an institution that las the right to govern SRM research, rather Ihan whe that is merely believed to hate that right, we focus on the normative sense of legitimacy.

Political philosophers also distinguish between the legitinacy of political inslifutions and the legitinacy of decisions made by those institutions. To saly Ihal an institution is legitimate is to saly that with respect to some range of issues, it has the moral anthority to make binding decisions for the people within its jurisdiction. '15'lis bay that a particular decision is legitimate is to say that the institution has the moral right to decide that particular issue in the particular way that it has." "The distinclion between legitinate institutions and legitimate decisions matters becansc legilimate institutions can sometimes make illegitimate decisions. A decision might be

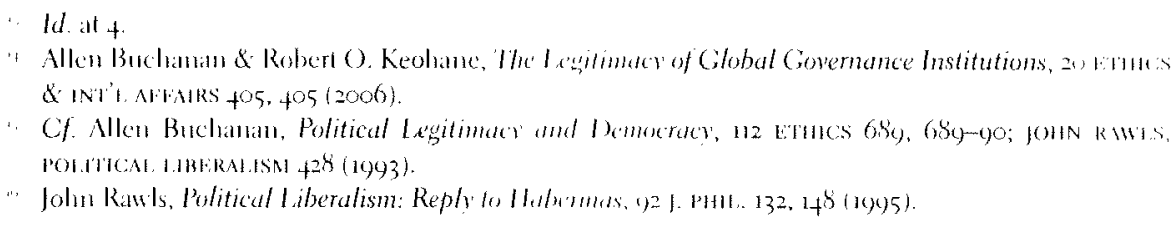


illegritimate because it does not result from the proper procedure." If, for instance, a legislative body requires half of its nembers to be present for a quormon, then a decision is illegitimate if it is made when only a third of the membership is present. Similarly, if a state's legislature cnacts a law that violates a right protected by the state's constitution, the law is illegitimate; the only legitimate procedure for albridging that right is to change the constitution. A decision could also be illegitimate if it is grossly moust." Although states can be legitimate without being perfectly just, not even a legitimate govemment of a legitimate state has the moral authority to violate the basic rights of its citizens in systematic ways. lior instance, procedural propriety presumably would not confer legitimacy on a decision to strip a particular etlmic minority of basic civil rights.

In political (i.e., collective) decision making, legitmacy plays the role that cons.m plays in individual decision making. Anyone who voluntarily cedes anthority orer some range of issues to a trade union, a board of directors, a government, or a similar decision-making body thereby acknowledges that legitimacy is an appropriatc standard for evaluating collective decisions. As Allen Buchanan puts it, consent, despite its prominence in social contract theorists' acconts of political legitimacy, is "ill-suited to the political world" because "politics seems to be concerned ... with how to get along when consent is lacking." "w

As "participation" in an SRM experinent is a collective choice, not an individual one, rescarchers whose experiments have the legitinate approval of all appropriate institution will satisfy the demands of the Principle of Respect. An appropriate institution, in this context, is one with the global political legitimacy to mathe decisions about SRM experiments.

For the purposes of assessing possible models for a global SRM governance institution, we adopt Allan Buchanan and Robert Koohane's Complex Standard of legitimacy for global govenance institutions (C.C.ls). In broad strokes, the Complex Standard has three parts, each of which we elaborate on below. First, a legitimate institution must enjoy the ongoing consent of denoeratic states. Second, a legitimate institution must meet certain "substantive" conditions: namcly, it must exhibit "minimal moral acceptability," maintain its institutional integrity, and deliver positive benefits relative to alternative feasible institutional arrangements. 'l'hird, a legitimate institution must manifest certain "epistennic" or "deliberative virtues," which provide sufficient tramsparency and accombability to ensure meaningful participation by and due comsideration of its stakeholders.

Id. at 175

ir $1 d$, at 176 .

11) Buclianan, supra nole 15, al 6xy)-700. See also kawis, supra note 15 , at 393 and +28 .

$2:$ Buchanan \& Keolane, supra note 1 , at fi7-20). 
The consent of democratic states is a necessary, but not sufficient, condition for the legitimacy of a CGI. Buclanan and kicolane worry primarily that the "claain of delegation" tying C.CIs to the individuals that legitimize the states that legitinize the GCls niay becone too long. With such a long leash, the bureaucrats in a C,Cl nay not be appropriately responsive to stakeholders' needs. In the case of SRM, at least, there is a further concern. Several major states - certainly China and arguably Russia - are not democratic in the relevant sense. Indeed, a great deal of the world's population lives in nondemocratic states. Given the potentially broad impact of the decision to be made, we are reluctant to claim that an institution regulating SRM could be legitinate without the consent of at least the larger, less illegitimate nondemocratic states."

The "substantive" conditions for legitimacy conbine the need to deliver positive net benefits with the need to avoid gross injustices, corruption, and abuses of power. Buclianan and Keolane explain that CCIs meet the first substantive condition, "minimal morally acceptability," if they do not "persist in conmitting serious injustices," where a serious injustice consists in violating human rights. ${ }^{22}$ They understand "institutional integrity" to mean adlierence to a GGI's stated mission and methods. Corruption eroded the integrity of the UN Oil-for-Food Program, for example, because it permitted Saddan Hussein and other government officials to profit from the sale of oil, even though the program aimed to ensure that Iragi oil revemes would benefit the Iraqi public without further enriching him. ${ }^{23}$ Even if a GGI meets these two substantive conditions, it must deliver positive net benefits, as compared with other feasible institutional arrangements. (One feasible arrangement, of course, is the absence of a formal institution.)

The most important part of the Complex Standard, in our view, is the requirement that GGIs manifest the "epistemic virtues" of transparency and accountability. ${ }^{24}$ These virtues set democratically legitimate GGIs apart from global bureaucracies staffed by unaccountable technocrats and operating opaquely. Even if the UN General Assembly unanimously voted to establish a GGI to be rum by technocratic experts, and even if benevolent experts at the GGI met Buchanan and Keohane's substantive conditions for legitimacy, the GGI would lack legitimacy if the global public had no effective way to monitor and sanction the GGI's activities. A benevolent dictatorship is illegitimate, even if initially installed with public approval, because of the ease with which it can abuse its power; a benevolent but opaque and unaccountable technocracy is illegitimate for the same reason.

\footnotetext{
2 But ef Buchanan \& Keobane, supranole 14 . at $+12-14$.

:2: Id. at +19

$=3$ Id. at $+2 z-23$

$+1 d$ at $+24-33$
} 
Buchandn and Keolane's epistemic virtues serve to overcome the informational asymmetries that enable bureaucracies to subvert the will of their creators. To be transparent and accountable, a GOI must provide information on its goals and behavior in a format that is accessible and intelligible to transnational civil society. Furthemore, there must be mechanisms by which civil society can challenge the GGl's goals, standards, and methods and sanction the GGI for failing to meets its standards or achieve its goals. Manifesting these virtues involves actively engaging with transnational civil society, usually through national governments and international NGOs. Enguging all groups that are significantly affected by an institution may require engaging actors outside the usual circle of governments and $\mathrm{NGO}_{\mathrm{s}}$. This is certainly the case with SRM, as those most vulnerable to decisions about SRM experiments may not be well represented by existing NGOS or governments. ${ }^{25}$

In light of Buclanan and Keolane's discussion, we believe that a 6 , Gl that met the Complex Standard would have the political legitimacy to make decisions about conducting SRM experiments. We do not clain that such an institution could make decisions about deploying SRM for non-research purposes. Such deployment would involve more serious, longer-tem consequences and commitments than an SRM experiment, and so decisions about deployment may require stricter conditions for legitimacy. 'T'hese stricter conditions may' consist merely in more stringent application of the Complex Standard, or they may involve the introduction of further criteria, such as a larger role for the UN General Assembly or other, more directly representative bodies.

\section{MODELS FOR AN INSTITUIION TO MANAGE SRM RESEARCH}

During the twentieth century, people developed or considered various institutions to govern a wide range of international activities. We examine three of these institutions as possible models for an institution to manage SRM research. None is a perfect analogue because SRM experiments present a new kind of global problem: never before has the world collectively decided whether to conduct experiments that could affect so many people's welfare in such significant ways. Individual states have made momentous decisions, major intemational organizations have implemented policies with global consequences, and humanity has stumbled collectively into patterns of behavior - such as fossil fuel use - that reshape the globe. None of these decisions, however, constituted an intentional choice by the global public to undertake a risky global experiment for the sake of acquiring new knowledge. Thus, our purpose in reviewing existing GGls is not to find a single, complete model

* See Pablo Suare, Jason Blackstock \& Marten van Aalst, Towards a People-Contered Framework for Geoengineering (overnance: A Humanitarian Perspective, 1 geolnginetrang Q. 2, $3(2010)$. 
for managing SRM. Instead, we draw what lessons we can from each case about lle ways that an SRM governance body could satisfy the Complex Standard for legitimacy.

\section{+.1 Institutions for Managing Nuclear Weapons}

SRM would enable humanity to alter the world in a relatively short period of time. Nuclear weapons gave humanity power to alter the world overnight. Given the power of nuclear weapons, the international community has developed a suite of institutions to regulate them. These institutions aim to constrain nuclear testing, curb muclear proliferation, and reduce the size and danger of existing nuclear arsenals. In this section, we focus mainly on institutions that constrain nuclear testing. We also consider the hypothetical International Atomic Development Agency (IADA), which the United States proposed in 1946 as part of the Baruch Plan.

\subsubsection{Nuclear Test Ban Treaties}

Between 1963 and 1996 , the international community concluded four treaties that constrain the testing of nuclear weapons. These are the 1963 Treaty Banning Nuclear Weapon 'lests in the Atmosphere, in Outer Space, and Under Water ("Partial Test Ban 'Treaty" or P'T'B'T); the 1970 'Treaty on the Non-Proliferation of Nuclear Weapons (NPI); the 1973 Treaty on the Limitation of Undergromnd Nuclear Weapon Tests ("Threshold lest Ban 'Treaty" or 'TTBT); and the 1996 Comprehensive Nuclear-Test-Ban Treaty (CTB'T). We refer to these treaties collectively as the "Test Ban Treaties" (TB'Ts). The TBTs - especially the NPT - form part of the larger international effort against proliferation and toward disarmament. The history of that larger effort, and of the 'TB'Ts in particular, holds important lessons for those interested in forging international agreements about SRM. In other words, the role of transnational civil society, ${ }^{36}$ the importance of vested interests at the domestic level, ${ }^{27}$ the ways in which nuclear-weapon states promised to protect non-muclear-weapon states from nuclear aggression, ${ }^{25}$ and the various political obstacles confronting diplomats in shaping the TB'T $\mathrm{s}^{2 y}$ would likely find echoes in the process of shaping SRM treaties. In this chapter, we leave many of those lessons aside to focus narrowly on the question of the legitimacy of the 'TB'S' constraints on nuclear weapons tests.

so See Rebecca Johnson, Unfinished Business: The Negotiation of the CI'B'T and the End of Nuclear Testing 25 (2009).

27 See johnson, supra note 26 , at 32, 41, 47 .

*t See S.C. Res. 255, U.N. Doc. S/RES/255 (Junc 14), 1968).

29) See jolinson, supra note 26, at 9-172. 
Nuclear weapons tests share important features with SRM experiments. Like SRM experiments, nuclear weapons tests threaten the global public directly, through exposure to radioactive fallout, and indirectly, by contributing to the development of dangerous technologies. Furthermore, states conduct nuclear tests in part because they believe that the development or maintenance of nuclear weapons may be vital to their national interests in the future - a view that some states may one day adopt with respect to SRM technologies.

The PTBT bans all nuclear explosions except those conducted underground. $3^{\circ}$ (The treaty exempted subterranean tests partly because of technical difficulties in distinguishing such tests from earthquakes.) The treaty's purpose was to curtail the testing of nuclear weapons in order to slow the nuclear arms race and protect the public from radioactive fallout. Beginning in 1955 , small multilateral conferences of major powers struggled for eight years to negotiate a ban on nuclear testing. Frustrated by the failure of these negotiations, the United States, the USSR, and the UK hammered out a treaty over the course of ten days in Moscow in $1963 .{ }^{3+}$ This is not to say that the multilateral negotiations were fruitless. They laid the groundwork for the final negotiations, helping to ensure that the negotiations in Moscow generated a treaty to which most states consented. One hundred and eight parties signed the treaty that fall. The treaty has 124 parties, including all of the nuclear-armed states except China, France, and North Korea, none of which signed the treaty. ${ }^{32}$ The PTBT did not involve the creation of a separate bureaucracy; the treaty implicitly relies on state parties to detect violations of the treaty.

In the years following the PTBT, the NPT emerged from bilateral and multilateral negotiations, including discussion in the UN General Assembly. The treaty prohibits the transfer of nuclear weapons-related technologies from nuclear-weapon states to any other State, and it prohibits non-nuclear-weapon states from developing or acquiring nuclear explosives. ${ }^{33}$ Rather than prohibiting certain kinds of nuclear tests, it prohibits tests by certain actors - namely, states that had not already detonated a nuclear explosive prior to January $1,1967 .{ }^{34}$ The treaty opened for signature in 1968 and entered into force in 1970 . It currently has 190 parties, indicating broad global consent. ${ }^{35}$ The most prominent dissenters are India, Israel, and Pakistan.

30 See Treaty Banning Nuclear Weapon Tests in the Atmosphere, in Outer Space and Under Water, Aug. $5,1963,14$ UST 1313, 480 UNTS 4 , at Art. I.

" U.S. Department of State, Treaty Banning Nuclear Weapon Tests in the Atmosphere, in Outer Space and Under Water (n.d.), http://www.state.gov/t/isn/4797.htm.

; See id.

${ }_{33}$ Treaty on the Non-Proliferation of Nuclear Weapons, July 1, 1968, 21 UST 483, 729 UNTS 169 at Art. I-II.

34 Id. at Art. IX.

${ }^{35}$ United Nations Office for Disarmament Affairs, "Non-Proliferation of Nuclear Weapons (NPT)" (n.d.), http://www.un.org/disarmament/WMD/Nuclear/NPT.shtml. 
India has been a particularly vocal crilue of Ihe lrealy, which it seces as entrenching mernational power differentials ${ }^{\text {th }}$

The NI'l relies heavily on the lulemalional Atomic linergy Association (LAEA) lo monitor compliance with the treaty's provisions. Although this makes the IAFA antral to the global nomproliferation regine, the IAEA plays only an indirect role by helping to enfore the regimes prolnibiting nuclear weapons tests.

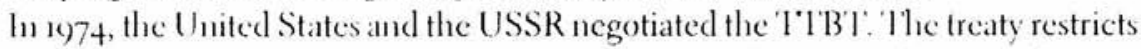
mderground tests to viclds of less than 150 kilotons." Concens about verification valled ratification for sixteen years until highly technical protocols were devised Ihrough bilateral meetings in the late 1980 s. Following the acloption of these protocols, both parties ratified the treaty in 1990. The United States and Russia remain Ihe sole parties to the treaty: ${ }^{\text {in }}$ Despite this delay, both partics amounced in 1976 Ihat they would abide by the 15 o-kiloton limit," and according to the officially stated vields of their muclear tests, both have done so. " Critics condemu the treaty as a ruse by which the superpowers could claim progress on disarmanent without imposing meaningful limits on the development of their melear arsenals. ${ }^{+1}$

The ('l'B'l', which would ban all unclear explosions of any kind, was opened for signature in September 1eg6 bul has yel to enter into force. As of 2010 , the treaty is awaiting the ratification of nine key states: China, liggpt, lndonesia, lndia, Iran, Israel, North Korea, Pakistan, and the United States. Some of these states lave signed the treaty; others hase not. : liven without the C'I'B'T' in forec, however, nuclear tests have all but ceased. None of the major muclear-weapon states lave conducled tests since $199^{6}$; lndia, Pakistan, and North Korea have each conducted two tests since then ${ }^{\text {t }}$ ' 1 'he ('I'I'l' arguably played a causal role in this reduction in testing. China and France stated that their funal tests in 1996 were meant to avoid the need for further testing onee they had signed the C'I'B'I'. The largest reduction, though, came carlier from the end of the Cold War, which cuabled Russia, the UK, and the United States to cease testing in the carly royos.

(6) jounson, supra uole 2(), at ic).

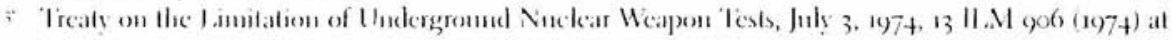
Art. 1.

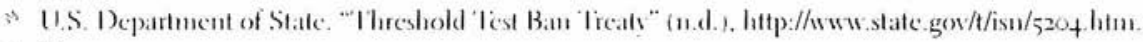

;) Id.

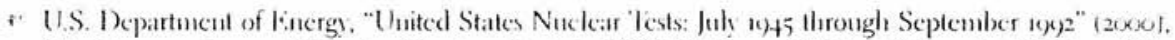

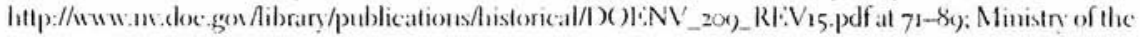

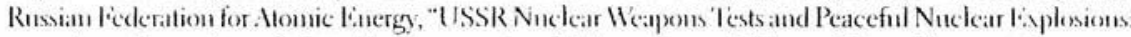

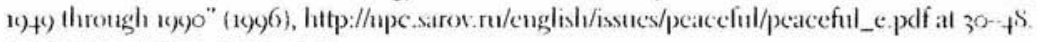

- jomivson, supra nole 30 , at 20 .

F ld. al $3-4$.

45 Comprelicusice Nuclear 'Tesi-Ban Treat! Organzation Preparatory Committec, "Nuclean Ievine: $19+5-2009$ " (n.d.). hillp://www.ctbto.org/nuclear-lesting/history-of-1uclear-testing/unclcar-hev/un:; 19) $+5-2000 /$ page-7-nuclear-testing-19) $+5^{-2009}$. 
like the PTB', the C'I'B'I' emerged from a long series of discussions in various forums. Anong the most inportant of these forums was the Group of Scientific Experts (GSE), which had collaborated since 1976 to develop the technical knowledge needed to monitor and verify compliance with a test ban." Decades of discussion about a C'I'I' culminated in two years of negotiations in the Conference on Disamannent (CD) from 1994 to 1996 . Despite substantial progress in those two years, Indian opposition still threatened to scuttle the treaty. Only Belgian and Australian parliamentary maneuvering brought the draft treaty out of the CD and into the UN General Assembly. The General Assembly endorsed the draft by an overwhelming majority. ${ }^{5}$

The CTBT calls for a dedicated intemational organization to monitor compliance and implement the treaty; a Preparatory Commission has worked since 1997 to lay the groundwork for implementation. Tlie central task of the Comprehensive Nuclear-Test-Ban Treaty Organization (C'IBTO) is to monitor compliance with the treaty. 'T'his involves operating the International Monitoring System (IMS), which monitors for physical and chemical signs of a nuclear explosion, and if necessary, conducting on-site inspections after suspected muclear tests. "The IMS consists of 337 facilities around the world. 'These facilities monitor seismic events, hydroacoustic activity, atmospheric infrasonic waves, and airbome radionuclides.$^{t^{6}}$ The data they gather is channeled to the International Data Centre (IDC) in Vienna and made available for civilian research. The IDC provides both raw data and quality-controlled data bulletins to member states, along with software and training to help member states interpret the data. $\$$ 'This arrangement grew out of negotiators' insistence that the IDC make its data transparent to member states that lack the resources to interpret raw data. ${ }^{+\infty}$

Collectively, the TBT's provide a framework by which the international community has forbidden various classes of dangerous experiments. What lessons do the 'T'B'T's hold for those looking to create a legitimate SRM GGI?

First, the TBTs suggest a way to achieve some progress, ethically speaking, with respect to SRM experiments, even if the international community cannot reach perfect agreement on whether or how to conduct such experiments. The 'TB'T's do not constitute the global community's consent to any particular test; they merely

H See jolinson, supra notc 26 , at 149 .

t5 Id. at $4^{6-1+2 .}$

4) Comprehensive Nuclear-lest-Ban Trealy Organization Preparatory Commission, The ClBT Verification Regime: Monitoring the Earth for Nuclear Explosions 2 (2004), http://ww.ctbto.org/ filcadmin/aser_upload/public_information/2oon) Nerification Regine final web.polf fluereinafter C'IB'TO Preparatory Commission!.

†. Id. alt 5 .

is jominson supra note 26 , at 149 


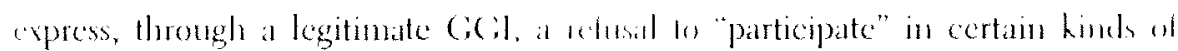
"xperiments. The decision to perform mue lear lests or not remains in the laumels of hrose states that are anthorized to do so moler the NPT, or have refused to foin lle NPl'. If the intemational commonity cammol agree on which SRM experiments ilat? would like to perform, they might at least agree on what kinds of SRM experincents Hey will not tolente. Conducting an SRM experiment in the gaps left by a partial lest ban would still be deeply ethically problematic, as it still anounts to hmman aperimentation without consent. However, even if it only had the power to restrict Whe kinds of experinents that may be performed, a politically legitimate SRM (:C I would increase the global public's control over the climate and might help deter the most dangerous experiments. Although it would not satisfy the Principle of Respect, it would be ethically better than nothing.

Secoind, the history of the 'T'B'l's demonstrates that meaningful treaties that enjoy widespread international support - and thus satisfy one of the criteria in the Complex Standard for legitinacy - can emerge from small multilateral negotiations. The I'I'BT', for instance, was wlimately negotiated by just three states, and yet it covers wer one hundred states. The lesson for SRM is that, if wider negotiations falter, a relatively small working group way be able to produce a treaty that the broader international community funds acceptable.

Admittedly, none of the 'I'B'l's have attained muversal support. Fach lack the support of at least one major power, including at least one major demoeracy: China

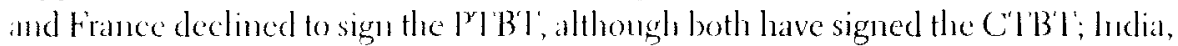
Israel, and Pakistan reject the NI'l'; China, India, Indonesia, Iran, and the United States, among others, have yet to ratify llse ('I'B'!

Sonne of the differences between molear weapons and SRM, however, give reason to hope that multilateral negotiations about SRM may be nore productive than negotiations over molear test bans. 'I he' I'B'T's were negotiated in a context in which some states already lad developed, tested, and deployed nuclear weapons; no one has yet tested or deployed SRM technologies. 'I'luss, a treaty that prohibits the further development of SRM technologies would not institutionalize existing incegualities in the way that the NPl' did. Furthermore, molear weapons pose a greater technological challenge than (some forms of) SRM. Thus, many states could develop) SRM technologies, whereas fewer are capable of producing muclear weapons. If any state were to deploy such technologies, all states would face the consequences of an altered climate. 'This increases each state's incentive to seek genuinc international consensus relative to the nuclear weapons case, where each state had to worry nainly about unfriendly states with high technological capacity. These differences may facilitate agreements that enjoy eveu broader intemational support than Ha 'TB'I's do. Conversely, the relative ease of conducting SRM experiments provides many more opportunitics for political mancuvering. In principle, even small stales 
could threaten to conduct SRM experiments or withloold support from a treaty in order to extract concessions cluring the treaty negotiations. To the extent that larger states can link SRM to other issues on which they have leverage over smaller states, however, such threats would not be particularly credible.

'Third, any SRM GGI will need the capacity to collect and analyze massive quantities of data. 'The epistemic criteria of the Complex Standard requires that an SRM GGI include an international organization that can relay this data to interested parties in a comprehensible format. The IMS and IDC provide a useful model for collecting and disseminating that data in an epistemically virtnous way. The dual military-civilian use of the IMS also suggests that SRM monitoring conld piggyback on existing facilities.

One of the linnitations of the analogy between the T'B'T's and SRM is particularly instructive, too. Continued nuclear weapons tests provided no global benefit. Thus, the 'I'B'l's provide a net benefit to the global public, as required by the Complex Standard, although their benefit might not be as great as that of some alternative institution (e.g., a CTBT that is more likely to enter into force). SRM experiments might provide a global benefit, either by preparing the global public to deploy SRM effectively or by revealing that SRM is unwise. In the event that SRM experiments turn out to be beneficial, an SRM GCl modeled on the 'I'B'I's would prove to be detrimental to the global public if it prohibited the necessary experiments. T'he GCI would therefore fail to meet the Complex Standard. One challenge of SRM, of course, is that if SRM experinents do turn out to be necessary, we might not recognize that fact until it is too late. 'l'hus, we may not know that the GCil has been detrimental - and to that extent illegitimate - until after the fact.

\subsubsection{International Atomic Development Agency}

Before the Cold War set in, the United States envisioned a very different regime for managing nuclear weapons and nuclear technology generally. In June 1946, Bernard Banch urged the UN to create a powerful international body - the lntemational Atomic Development Agency (IADA) - that would effectively control all aspects of nuclear technology. ${ }^{+9}$ This so-called Baruch Plan largely followed an carlier report by the U.S. State Department, which had become known as the Acheson-Lilienthal Report. Under the Baruch Plan, the IADA would exercise close control over all plases of nuclear activity. 'Through ongoing surveys, it would identify all global deposits of

+* Bernard M. Baruch, Statement of the United States Policy on Control of Atomic Einergy as Presented by Benard M. Barnch, lisq., to the (lnited Nations Atomic Energy Commission (June 14, 1946), reprinted in U.S. DEP'T OF STATE, PUB. 2560 , THE UNTTED STATES AND THE UNTTED NATIONS, RLP. SERIES NO. 2, THE UNITED SIATLS ATOMIC ENFRGY PROPOSAls $(1946)$, available at hitp://ww. altomicarchive. con/Docs/Deterrence/BanchPlan.shml [hereinafter Baruch Plan]. 


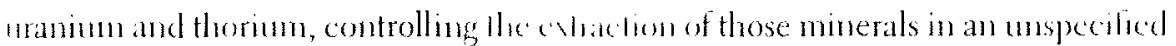
mamer. It would "exercise complek mamaperial control" over plants produchos fissile materials, and it would own and control the output of those plants. "I the IADA would maintain a monopoly on rescarch into nuclear explosives, although lhe manufacture of nuclear weapons would be prohibited, and it would becone the world's leading authority on peaceful uses of nuclear energy. 'I'lirough licensing and inspection arrangements, it would control any use of nuclear technology, providing materials for such activities "under lease or other arrangement." 51 This combination of expertise, ownership, managenent, and inspection would enable the IADA to understand, recognize, and detect misuses of nuclear technology while promoting its peaceful use in an equitable, secure fashion. ${ }^{\text {jz }}$

Baruch insisted on swift sanctions against violators. Baruch specifically insisted that such sanctions be immune to veto by the permanent members of the UN Security Coumcil.: By a bare majority vote in the Security Council, the UN would lave been able to sanction states that the IADA ruled to be in violation of the international muclear regime.

In part because of Barncli's insistence on reto-proof sanctions, his proposal ended in a diplomatic stalemate. The Sovict Hnon rejected the IADA out of concen that the United States would retain its nuclear arsenal and that the IADA would becone in instrument of U.S. policy. In 1949), the Sovict (Hion detonated its first muclear weapon. 'l'he arms race had begum, and the prospect of centralized global governance of nuclear weapons fadecl.

Given both its discretion in the development of nuclear fuel and certain kinds of nuclear research, as well as its power in sanctioning sovereign states, the IADA would have exercised considerable anthority in making collective decisions about nuclear techmology. Assuming that no state managed to evade the IADA long enough to develop miclear weapons on its own, the IADA would have exercised a complete monopoly over a world-changing technology.

Thus, the IADA, as proposed by Baruch, constitutes a conceivable model for an SRM governance institution. It would have been an international organization for research into a sensitive, dangerous suite of technologies, about which it would have made important decisions on behalf of the international community - including decisions about experimental uses of the technology. If it had the will to do so, such an organization would be better positioned than any viable altemative to ensure that researchers behave ethically - both with respect to the political legitimacy of their

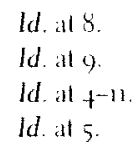


decisions and with respect to satisfying other requirements of ethical conduct, such as those in our proposed ethical framework. 5 t

The degree to which such a program would actually ensure ethical conduct of SRM experiments, however, would depend heavily on the structure of its decision-making processes and on the degree to which its personnel meet the substantive conditions and exhibit the epistemic virtues required by the Complex Standard. One concern about such an organization is that the technocrats who run it may develop goals or preferences that diverge from the interests of the international community. Some staff members' enthusiasm for SRM might exceed that of the global public in dangerous ways. Some might be susceptible to pressure from particular states whose views differ from those of the international community, or might obscure information to protect or further their own careers at the expense of public transparency and accountability. Any of these factors could cause the organization to violate the second or third criteria of the Complex Standard. Thus, placing so much responsibility for SRM research in the hands of unelected technocrats might lead to politically illegitimate institutions or decisions.

The unhappy fate of the Baruch Plan, however, provides an instructive lesson for thinking about the conditions required for widespread international acceptance of an SRM GGI, as required by the Complex Standard. The Baruch Plan was infeasible because it concentrated too much power in an intemational organization. Some states may have bristled at ceding such power to an international body. Others, such as the Soviet Union, may have feared that the IADA would have been too beholden to the United States. Assuming that contemporary states would likewise reject any GGI that is either too powerful or too likely to be dominated by one or more great powers, the international community would need to design an SRM governance institution carefully in order to give it an appropriate amount of power and international accountability. Otherwise, the SRM GGI would be unlikely to secure the multilateral consent required for legitimacy. Still, if the international community decides to delegate limited authority for SRM experiments to an INGO, the IADA offers one possible conception for doing so.

\subsection{Institutions for Managing Global Commons}

A stable planetary climate represents a type of global commons - a global public good that no single country is capable of controlling. 55 SRM experiments involve a rapid, deliberate change in the climate - a change that could have negative conse-

s4 See Morrow et al., supra note 3, at 3-6.

55 Marvin S. Soros, Garret Hardin and Tragedies of Global Commons, in handbook of Global environmental politics 35, 45 (Peter Dauvergne ed., 2006). 
quences for some persons and ecosystems. 'I hus, GGls designed to manage global commons provide another type of model for an SRM GGI.

Like a stable climate, Antarctica is viewed by many as a global commons. 'The Antarctic Treaty System (ATS), established in 1959 by the twelve countries active in Antarctica during the International Geophysical Year, sought to ensure the peaceful use of this commons for scientific exploration..$^{56}$ Today, the Treaty has forty-eight parties. 'Twenty-eight of these parties are active in Antarctica and therefore have decision-making authority as Consultative Members; the remaining twenty have observer status as Non-Consultative Members. 57

The original Antarctic Treaty focused primarily on freezing territorial claims and establishing a legal framework for exploration. Environmental issues entered the ATS through later protocols, the most comprehensive of which is the 19gi Protocol on Environmental Protection (the Madrid Protocol). The Madrid Protocol, which entered into force in 1998 , is perlaps most broadly known for establishing a fifty-year moratorium on exploiting mineral resources in the Antarctic; more relevant to our analysis, it also established a set of principles regarding environmental protection, an intergovernmental body of scientific experts to offer advice on environmental issues, a procedure for environmental impact assessment of activities in Antarctica, and a consultative process regarding these activities..$^{55}$

Article 3 of the Protocol lays out a set of principles that gives primacy both to ethical concerns and scientific research. These principles require that activities in the Antarctic be planned and executed "so as to limit adverse impacts on the Antarctic." ${ }_{59}$ The article also mandates monitoring of risky activities and requires that such activities be modified or stopped if monitoring reveals adverse impacts. ${ }^{\text {to }}$ In principle, this article requires states parties to give significant weight to environmental, ethical, and even aesthetic values in regulating governmental and nongovernmental activities in the Antarctic. Among the ethical principles recognized are those akin to our Principles of Minimization and Respect."

Article $n$ establishes the Committee for Environmental Protection (CEP). The CEP consists of representatives from each Party to the Protocol, along with their advisors. Parties to the A'TS who are not Parties to the Protocol, as well as relevant NGOs invited by the CEP, may attend meetings as observers. The Protocol instructs the CEP to provide technical advice on the implementation of the Protocol, including

st Antarctic Treaty, 1 Dec, 1959, 402 UNTS 71.

57 Secretarialt of the Antarctic Treaty System, "Parties" (2008), http:/wwwats aq/devAS/ats partics.aspx.

i8 Madrid Protocol on Environmental Protection to the Antarctic Treaty, 4 Oct., 1991, 30 Il.M1 1455 [hereinafter Madrid Protocol].

59 Id. at Art. 3, para. 2. (See the Appendix to this chapter for the complete text of Article 3.)

to Id. at Art. 3, para. 2(d)-(e), 4(b).

in See Morrow et al, supra note 3 , at 3-6. 
advice on the effectiveness of parties' efforts to comply with the Protocol..$^{62}$ Because the CLP must release reports on its sessions to states parties and to the public, ${ }^{63}$ it could alert interested states and members of civil society to activities that run contrary to the Protocol. Ultimately, however, the CEP's role is strictly advisory; it has no power to affect decisions directly.

The states parties hold ultimate responsibility for assessing the envirommental impact of their activities, although they must discuss their assessment of some activities with the other Parties and the CE.P. As laid out in Article 8 and Annex I, the Protocol recognizes three tiers of activities in the Antarctic: those determined by national procedures to have "less than a minor or transitory impact," those "likely to have no more than a minor or transitory impact," and those likely to have "more than a minor or transitory impact." ${ }^{+}$Activities falling into the second category reguire an Initial Environmental Evaluation characterizing the activity, alternatives to the activity, and likely impacts. ${ }^{65}$ Activities falling into the third category require a Comprehensive Environmental Evaluation (CEE), which describes the state of the environment prior to the activity; the activity and all relevant alternatives, including the alternative of not proceeding with the activity, along with the expected consequences of each altemative; the direct and indirect inpacts of the proposed activity; the cumulative impact of the proposed activity, given existing and currently planned activities; the methodology and data used to forecast consequences; the measures that could be taken to monitor the effects of the activity and to minimize or mitigate them; a nontechnical summary of the above information; and the contact information for the author(s) of the CEE.

The draft CEE must be circulated for review to the public, to the Antarctic 'Treaty parties, and to the CEP. In principle (although not always in practice), the activity cannot proceed until the draft CEE, has been considered by the Antarctic Treaty Consultative Meeting on the advice of the Committee, and a final version of the CLE must respond to the comments raised in the review process. The draft and final CLE must be made publicly available. ${ }^{67}$ (Once the activity begins, its impacts nust be monitored. ${ }^{68}$

Christopher Joyner highlights a number of potential weaknesses in the Madrid Protocol process. ${ }^{\text {ng }}$ The role of the Environmental Impact Assessment consultative

the Madrid Protocol, supra note 58 , at Art. 11.

a: Id. at Arl 11, palra. 5

${ }^{14}$ Id. at Art. 8, para. 1.

"s Madrid Protocol, supra note 58, at Annex I, Art. 2

rd, Id. at Arnex 1, Art 3, para. (1)-(2).

i- Id. al Anmex 1, ATt. 3, paral. (3)-(6).

(2) Id. at Art. 8.

GH CHRISTOPHER C. JOYNER, CONERNING THE FROZEN COMMONS: THE, ANTARCTIC RLGINIE AND ENVIRONMENTAL. PROTECTHON 165-7+(1998). 
process is fundamentally hortatory; although individual governments must respond to comments under the Protocol, they retim the final decision on whether to proceed with a specific activity. In addition, the boundaries between the different categories of activities are ill-defined, left to some combination of party judgment and the evolution of precedent. More broadly, the mechanism of enforcement of the Protocol in general is unclear: parties are to enforce it through laws and regulations, and shall exert "appropriate efforts, consistent with the Charter of the United Nations" to ensure that other parties do, $7^{\circ}$ whereas an Arbitral Tribunal or the International Court of Justice is empowered to settle disputes, but again these are largely hortatory procedures. ${ }^{71}$

Despite these problems, the Madrid Protocol provides a GGI model that directly addresses clements of scientific research ethics and the Complex Standard. In particular, the consultative process for assessing proposed activities exemplifies the transparency and stakeholder engagement necessary for legitimacy. CEEs must contain nontechnical sumnaries, making them more easily digestible by states and civil society. Draft and final CEEs, along witl reports on CEP sessions, are distributed to states parties and the public ${ }^{27}$ 'This increases the transparency of the international governance of Antarctic activity, as required by the Complex Standard.

The Madrid Protocol does not, however, provide an effective means for citizens of one state to hold another state or its citizens accountable for behavior that violates the Protocol. T'The hortatory nature of the EIA process would be even more problematic in the case of SRM, where the incentive to ignore the exhortations of other states might be much greater than in the Antarctic case. If an SRM GGI had no more power than the CEP does in Antarctica, then it could not deter even a moderately motivated state from conducting SRM experiments. Conversely, an SRM GGI that could, at its own discretion, prohibit certain experiments would be too powerful - too much like Baruch's proposed IADA - to be feasible, and a CGI that could prohibit experiments if and only if they violated constraints laid down in a treaty would be more like the CTBT than the CLP. Thus, replacing the hortatory model of the Madrid Protocol with something stronger brings us back to the nuclear weapons testing models.

Some elements of the Madrid Protocol could be readily adapted to the context of SRM research governance. Article 3 in particular would need just one major addition - impact on human populations - and a suite of minor contextual adaptations to address the global climate commons instead of the Antarctic "frozen commons." The conditions and processes for conducting environmental impact assessments

\footnotetext{
Madrid Protocol, supra note 58, at Art. 13, para. 1-2.

7 JOFNER, supra note 6o, at 166.

is Madrid Protocol, supra note 58, at Annex 1, $\Lambda$ rt. 3.
} 
transtate relatively casily to the SRM case as well. By requiring earlier involvencent from ollyer states and an SRM comnterpart of the CHP, along with scientific peer review of SRM research proposals, an SRM CGI might be able to exert more inflence on the shaping of proposals than the CEP exerts on proposed activities in the Antaretic. In any case, the Madrid Protocol provides a model for achicving the transparency recuired for legitimacy.

One challenging difference between the Antarctic content and the SRM context relates to the range of parties involved: the Antarctic 'Treaty engages in a consultative status with only the twenty-eight conntries active in Antarctica, whereas a CGI focused on SRM research would need to engage not just the comntries actively conducting research but the larger group of comntries with populations potentially at risk. SRM experments would also be likely to affect various states in more direct and more significant ways than Antarctic activities would, making disputes over SRM more heated than those over Antarctic activities. Broader and nore contentions discussions over SRM experiments may increase the time it takes to complete an EIA for any proposed experiment, as compared to the time it takes to complete an EIA for proposed Antarctic activities. The broader constituency of an SRM C,CI might also make it more difficult to craft an institution that enjoys sufficiently widespread acceptance to be legitinate.

As the preceding discussion shows, incorporating elements of the Madrid Protocol into an SRM C S I comld help improve the chances that the C.SI would retain its legitimacy under the Conmplex Standard, especially in terms of epistemic virtues and the delivery of positive net benefits to the global public. By providing a smaller but open formun for international deliberation about the decisions of individual states, it conld also improve the G(S's ability to reach legitimate decisions about particular SRM experiments, without recpuiring manmous consent from the international community about that experiment. As its processes are hortatory rather than coercive, however, an SRM GCiI modeled on the Protocol would have little power to rein in states that decided to pursuc SRM without international approval.

\section{CONCLUSION}

The international community is starting to consicler SRM as a stopgap or emergency measure for coping with the possible inadeguacy of medium-term mitigation efforts. As it would be foolish and unethical to deploy SRM without an adequate understanding of the technology, state or non-state actors nay decide to pursue SRM research - potentially including large-scale experiments - in the near future.

Large-scale SRM experiments, such as those involving the minection of enough reflective acrosols into the stratosphere to produce detectable climatic changes at the regional or global scale, involve significant ethical challenges. One important 
challenge is the need for politically legitimate decisions about whether and how to conduct such experiments; this requirement parallels the requirement for informed consent in medical experiments. Given that an SRM experiment is a global one, the decision to undertake it must be made by a politically legitimate GGH.

The Complex Standard for the political legitimacy of GGIs involves threc broad requirements. First, the CGI must enjoy the consent of most (democratic) slates Second, the GCI must meet certain substantive conditions, such as the avoidance of serious injustices, the delivery of positive net benefits, and the maintenance of institutional integrity. Third, the GGI must exhibit certain epistemic virtnes, such as transparency and accountability.

Other GGIs hold lessons for the design of a legitimate SRM GGI. Our analysis of the international nuclear testing regine suggests that a legitimate SRM CGI night evolve through negotiations among a smaller, more manageable group of powers, as long as the CGI itself receives the approval of the UN. It also suggests that, in the absence of a GGI empowered to authorize particular experiments, an institution with the legitimate authority to prohibit certain classes of experiments conld protect the world against the most ethically problematic ones. As our analysis of the Madrid Protocol to the Antarctic 'Preaty suggests, an institution recuiring and facilitating international discussion of any proposed SRM experiment would fare well on the third, epistemic criterion of the Complex Standard. Spelling out a set of principles that SRM experiments must follow, as the Madrid Protocol does for Antarctic activities, might increase the likelihood that such an institution could deliver positive net benefits, as required by the second substantive criterion of the Complex Standard. Our analysis of the proposed IADA suggests that a more powerful GGI, which might have the power to authorize specific experiments, may find it more difficult to meet the Complex Standard; such a powerful GGI may never enjoy the widespread support required for legitimacy, it is more likely to depart from the wishes of its creators, and it may do so in ways that violate the substantive and epistemic criteria of the Complex Standard.

The lessons from these case studies are complementary. $\Lambda$ single institution could prohibit certain classes of experiments, such as the 'TB'T', while facilitating international dialogue about the experiments proposed by states or non-state actors, like the Madrid Protocol. Such an institution would leave room for states to create a multilateral organization that combined research efforts without exercising the far-reaching powers and technological monopolies of the IADA. This is only a preliminary vision, of course, of an approach to managing SRM research, leaving nuany institutional issues open for further exploration.

The international community has never confronted a decision quite like that of conducting SRM experiments - much less to deploy SRM. That is why none of the institutions we consider provide perfect analogues for an SRM GGI. This is 
not the first time, however, that humanity has faced novel problems demanding umprecedented institutions. We believe that by learning from the successes and failures of the past, the international community can design an institution to managc decisions about SRM and SRM research in an ethically responsible way.

\section{APPENDIX: ARTICLE 3 OF THE MADRID PROTOCOL}

The complete text of Article 3 of the Madrid Protocol reads:

1 The protection of the Antarctic environment and dependent and associated ecosystems and the intrinsic value of Antarctica, including its wilderness and aesthetic values and its value as an area for the conduct of scientific research, in particular research essential to mnderstanding the global environment, shall be fundamental considerations in the planning and conduct of all activities in the Antarctic Treaty area.

2 To this end:

(a) activities in the Antarctic 'Treaty area shall be planned and conducted so as to limit adverse impacts on the Antarctic environment and dependent and associated ecosystems;

(b) activities in the Antarctic Treaty area shall be planned and conducted so as to avoid:

(i) adverse effects on climate or weather patterns;

(ii) significant adverse effects on air or water quality;

(iii) significant changes in the atmospheric, terrestrial (including aquatic), glacial or marine environments;

(iv) detrimental changes in the distribution, abundance or productivity of species of populations of species of fauma and flora;

(v) further jeopardy to endangered or threatened species or populations of such species; or

(vi) degradation of, or substantial risk to, areas of biological, scientific, historic, aesthetic or wildemess significance;

(c) activities in the Antarctic Treaty area shall be planned and conducted on the basis of information sufficient to allow prior assessments of, and informed judgements about, their possible impacts on the Antarctic environment and dependent and associated ecosystems and on the value of Antarctica for the conduct of scientific research; such judgments shall take account of:

(i) the scope of the activity, including its area, duration and intensity;

(ii) the cumulative impacts of the activity, both by itself and in combination with other activities in the Antarctic Treaty area; 
(iii) whether the activily will defumentally affect any other activity in the Antarctic Trealy :men:

(iv) whether teclunology and purcolures are available to provide for environmentally safe operations;

(v) whether there exists the cilpacin to monitor key environmental paraneters and ecosystem components so as to identify and provide early warning of any adverse effects of the activity and to provide for such modification of operating procedures as may be necessary in the light of the results of monitoring or increased knowledge of the Antarctic environment and dependent and associated ecosystems; and

(vi) whether there exists the capacity to respond promptly and effectively: to accidents, particularly those with potential environmental effects;

(d) regular and effective monitoring shall take place to all assessment of the impacts of ongoing activities, including the verification of predicted impacts;

(e) regular and effective monitoring shall take place to facilitate early detection of the possible unforeseen effects of activities carried on both within and outside the Antarctic 'Treaty area on the Antarctic environment and dependent and associated ecosystems.

3 Activities shall be planned and conducted in the Antarctic 'Treaty area so as to accord priority to scientific research and to preserve the value of Antarctica as an area for the conduct of such research, inchuding research essential to understanding the global environment.

4 Activities mondertaken in the Antarctic Treaty area pursuant to scientific research programs, tourism and all other govermmental and nongovernmental activities in the Antarctic Treaty area for which advance notice is required in accordance with Article VII (5) of the Antarctic Treaty, including associated logistic activitics, shall:

(a) take place in a manmer consistent with the principles in this Article; and

(b) be modified, suspended or cancelled if they result in or threaten to result in impacts upon the Antarctic enviroment or dependent or associated ecosystems inconsistent with those principles. ${ }^{\text {is }}$

\section{ACKNOWLEDGMEN'TS}

The authors wish to thank fan D. Lloyd and Robert Keohane for helpful comments on drafts of this chapter. 